\title{
The Environmental Imperative of Nuclear Disarmament
}

\author{
by
}

\author{
Mostafa K. Tolba, Ph.D. (London) \\ Executive Director, United Nations Environment Programme, P.O. Box 30552, Nairobi, Kenya,
}

Arthur H. Westing, M.F., Ph.D. (Yale)

Senior Research Fellow, Stockholm International Peace Research Institute (SIPRI), Bergshamra, S-171 73 Solna, Sweden; Adjunct Professor of Ecology, Hampshire College, USA

$\&$

\author{
Nicholas Polunin, D.Phil., D.Sc. (Oxon.), CBE \\ President, The Foundation for Environmental Conservation, 15 Chemin F.-Lehmann, 1218 Grand-Saconnex, \\ Geneva, Switzerland.
}

\section{INTRODUCTION}

Due consideration of environmental consequences of the use of nuclear weapons leaves us in no doubt that our 'only one Earth' is under increasing threats of wider devastation than ever before in history. For not only are there inexorably increasing human population-pressures causing more and more serious shortages and tensions, but our technological capability allows an unprecedented and highly alarming build-up of nuclear weapons of mass-destruction. On the other hand it seems likely that, if the facts of the present situation were sufficiently appreciated, people throughout the world would insist on remedy-on removal of the worst menace that has ever overhung Man and Nature. But while the facts are not widely appreciated, even if some may be known, the arms-race continues and reaches ever-more-dangerous proportions, with no likely remedy in sight. And even if all-out nuclear war is avoided, a flare-up through technological failure, mechanical or other accident, misinformation in any of the media*, malfunctioning or faulty feeding of computers, neglect of machines or of constructional defects, terrorist or insane action, or earthquakes or other 'acts of God', seems more and more possible with the ever-increasing buildup of nuclear weapons and of world-wide capacity for their production.

But what is the capability of destruction of this weaponry, and how serious is the threat which it poses? The present buildup of nuclear warheads is commonly said to number about 50,000 (the widely-quoted ' $U N$ figure'; cf. Anon., 1982; F. Barnaby, 1982), with a 'combined yield' exceeding the equivalent of some 13,000 megatons of TNT (Thunborg et al., 1981). That is some thirteen thousand million tonnes of TNT; yet the totality of conventional chemical explosives used throughout the history of Mankind has been less than one-fivehundredth of this amount, as it does not reach the equivalent in power of more than roughly 25 megatons of TNT. Simple arithmetic indicates that this 13,000 mega-

* Including the serious scientific press, as indicated by the Ehrlichs in their above Guest Comment: 'Old Myths Die Hard!' - Ed. tons is equivalent to nearly 3 tonnes of TNT for each of the ca 4,600 million people now living on Earth! Meanwhile the totality of nuclear detonations to date has reached only about 350 megatons-including all of the 1,300 or more test explosions and the bombs that were dropped on Hiroshima and Nagasaki in 1945 (cf. Westing, 1980 and in litt. 25 March 1983). Yet those two bombs - comprising the sole practical experience or 'experiment' of the kind which we have to date-were only of the order of one-thousandth of the strength of the large bombs now available, while the total explosive content of the current nuclear buildup of these weapons is equivalent to more than a million Hiroshima bombs.

As for the seriousness of the threat, we believe that, practically speaking, there could scarcely be any such event as a 'limited' nuclear war, that nobody would be better-off as a result of a nuclear war but would only see the entire world suffer grievously, and that nothing could be done medically or otherwise to save hundreds of millions of humans from sudden or lingering death from such a horrendous possibility-which must accordingly be avoided at all costs (Hiatt, 1981; cf. ICSU, 1982). Remembering human strengths and frailties and the possibilities of accidents and terrorist activities, it seems clear that the only real safeguard will lie in dismantling the existing capabilities and monitoring the world against any future buildup of nuclear or allied weapons of all kinds. Their continuation or proliferation would amount to insane folly, as their use could result in such a situation that any human survivors would indeed 'envy the dead'.

Let the three of us now deal in turn with environmental aspects as scientific (mainly biological) Authors who have recently expressed our views in (1) a statement to the Special Session of the United Nations General Assembly on Disarmament (Tolba, 1982), (2) a testimony before the US House of Representatives Committee on Science and Technology, Subcommittee on Investigations and Oversight (Westing, 1982; cf. also 1981 and Westing et al., 1982), or (3) a paper presented to the Académie de la Paix, in Monte Carlo, Monaco, on 25 March 1982, as a precursor to the present one - see also Polunin (1981), with some additional thoughts. Further details and documentation can be found for instance 
in the books of Westing (e.g. 1977, 1980), SIPRI (e.g. 1982), and W. Barnaby (1982), and in the special doubleissue of Ambio, the Swedish 'Journal of the Human Environment', Vol. 11, Nos 2-3, 1982.

\section{ENVIRONMENTAL ASPECTS AS SEEN FROM THE VANTAGE-POINT OF UNEP}

Nuclear weapons have the deadly capacity to destroy the life-giving systems on which we all depend. Plants, animals, and their habitats both terrestrial and aquatic, can be utterly devastated by nuclear detonations, of which the existing capability is sufficient practically to destroy The Biosphere and hence our life-support several times over. Thus the peoples of the Earth face the stark choice of survival or virtual annihilation, and far from getting better of late our prospects have deteriorated to a quite terrifying extent. $\dagger$

These grim facts were recognized by representatives of more than a hundred Governments when they met in Nairobi last year for the 'Session of a Special Character' of the UNEP Governing Council, and appealed to Governments and the world community to do their utmost to halt the arms race and thereby prevent a major threat to the environment - with concomitant huge wastage of intellectual and natural resources on armaments. Particularly threatened are the human population and the complex systems of The Biosphere, of which humans form an integral part and on which they are utterly dependent for the wherewithal of life. Also grievously threatened are the primary producers of the world, ranging from plant crops to the phytoplankton of the oceans on which most fishes, crustaceans, cetaceans, and other animal groups, are of course ultimately dependent. Besides nuclear weapons, chemical and biological ones also pose horrible dangers to the environment, involving deliberate threats of widespread and often lethal pollution or diseases through release, respectively, of toxic chemicals or harmful microorganisms. The results of the use of these and nuclear weapons, such as should, most unfortunately, be envisaged in any all-out war, could include disruption of agriculture, irreversible desertification, and the widespread disturbance of ecological balance for a very long time which in some instances might extend to centuries or even millennia.

It is unrealistic and dangerously complacent to think that any nation, however powerful, could 'win' a fullscale nuclear war, or that such an event could be localized, as it would destroy probably all the major cities of the Northern Hemisphere, killing the bulk of their urban populations by blast and fire, and also the bulk of the rural population by radiation. Moreover, many mil-

† Thus a referee emphasizes that it would be 'easy' to deflect the industrial use of nuclear energy into enriched plutonium and thence the development of nuclear weapons, and that this is probably already being done. Another authority feels that it would be inappropriate at this stage to attempt to deal with the recent proposal to neutralize nuclear missiles by means of lasers in the absence of proper study. We should, however, probably take very seriously the possibility of 'computer saboteurs'.Ed. lions in the Southern Hemisphere would be killed by radiation from fallout. The global climate could be seriously affected, as could the stratospheric ozone shield, and there could be serious genetic effects. Vegetation would be destroyed over vast areas, probably leading to devastating soil-erosion, with resultant extremely slow ecological recovery. As regards agriculture:

'A recent study has indicated that if a nuclear war occurred at the beginning of a growing-season, food production would be almost totally eliminated in the northern hemisphere, while if sunlight was blocked out by light-absorbing particles lofted up and spread in the atmosphere, much of the plankton-which provides the basis for most marine life--might die in about half of its oceans. In these grim circumstances, it would be difficult to conceive of continued survival for those who remained alive in the years following such a war' (Tolba, 1982).

\section{ENVIRONMENTAL ASPECTS AS SEEN FROM THE VANTAGE-POINT OF SIPRI}

As the world has never experienced a large-scale nuclear war, predictions of the environmental effects which it might have must remain widely conjectural. However, studies of the effects of the Hiroshima and Nagasaki attacks, of numerous test explosions, and of other circumstances including natural catastrophes, help to suggest the type of impact and extent of effects of such an event. These effects comprise four main categories which, with examples, may conveniently be treated as follows:

1) Blast-energy:- This comprises half or more of the energy of a nuclear bomb, and its dissipation is responsible for much of the physical damage that is caused on detonation. A single one-megaton airburst would knock down virtually all the trees occurring over ca 14,000 ha and force thousands of tonnes of water vapour, present in the lower atmosphere, into the stratosphere; as a groundburst it would blast out a huge crater, extending over perhaps 12 ha and with a maximum depth of $90 \mathrm{~m}$, and would thrust some 50,000 tonnes of rock and soil materials into the stratosphere as fine dust; burst underwater, it would lift tens of thousands of tonnes of water droplets into the atmosphere. Yet there now exist twenty-megaton bombs 'ready to go', and a greater-thanfifty-megatons' test has been detonated (Glasstone, 1964). Indeed it appears that there is practically no limit to the power of such detonations.

2) Heat-energy:-Another one-third or more of the energy of a nuclear bomb is dissipated in the form of an intense thermal wave, initiating wildfires over a vast area whose extent depends on the terrain, weather conditions, and vegetative cover. Thus on a clear and dry summer day, a one-megaton airburst might initiate wildfires throughout an area of 32,000 ha, and these would be likely to burn and spread for weeks, ejecting immense amounts of smoke into the atmosphere. Another effect would be the transformation of some 5,000 tonnes of the atmosphere into various oxides of nitrogen, which would produce a smog in the troposphere and degrade the ozone in the stratosphere. This would reduce the protec- 
tive barrier against excessive solar ultraviolet radiation, lead to increases in skin-cancers in humans, and have many ill-effects on other biota.

3) Radiation-energy:-The remaining $10 \%$ or so of the energy of a nuclear bomb is dissipated in the form of nuclear radiation. of which a portion is released in the initial burst and the remainder, much more slowly and widely, as radioactive fallout. A one-megaton groundburst would give a lethal dosage of nuclear radiation to all exposed vertebrate animals over some 36,000 ha (the 15-megatons' one on Bikini in 1954 deposited a lethal level of fallout over an area of approximately the State of Massachusetts, while the island group still remains unfit for human habitation despite intensive clean-up attempts!).

4) Synergistic effects:- Whereas the effects or expectations described above have usually concerned single nuclear detonations, we should also consider the (unfortunately far more likely) effects of detonations of several or groups of many bombs which would almost certainly be greater and more multifarious than a mere summation of the effects of individual bombs would suggest. Among the more disastrous of these synergistic effects would be those that could be set in motion by a large-scale injection of fine particles of dust and droplets of water into the stratosphere, by the addition of vast quantities of smoke to (or generation of smog in) the troposphere, and by the introduction of large amounts of oxides of nitrogen $\left(\mathrm{NO}_{\mathrm{x}}\right)$ into the ozone layer. The first of these could have long-term effects on climate (Nier et al., 1975), the second could (for one or even two growing-seasons) substantially reduce the primary production of ecosystems and debilitate agriculture (Crutzen \& Birks, 1982), while the third could permit increased amounts of damaging ultraviolet (UV-B) radiation to reach the Earth's surface, as indicated above. Owing to the lateral dispersion of ozone by diffusion in the lower stratosphere, this last effect would be more or less world-wide and could have a devastating effect globally on both natural and artificial ecosystems, whether terrestrial or aquatic (Nier at al., 1975; Tukey \& Peters, 1979; Kruger \& Setlow, 1982).

\section{FURTHER EFFECTS ON ECOSYSTEMS AND ECOLOGICAL SUCCESSIONS}

Although several important effects of nuclear detonations on species and, ultimately, biomes and their component ecosystems, have been dealt with above, some other ones, more specifically on the last-mentioned aggregations, should also be mentioned. Thus following a large-scale nuclear exchange, the ecological impact of the resulting enhanced UV-B radiation could be devastating on a global scale to both natural and artificial terrestrial ecosystems (Nier et al., 1975; Tukey \& Peters, 1979; Kruger \& Setlow, 1982). This is presaged by extrapolations from limited data which indicated that:

'... perhaps as many as $20 \%$ of the world's plant species might succumb either directly or indirectly, at least over much of their ranges, and an additional fraction of them would have their photosynthesis (food production) and growth impaired over wide areas. Moreover these debilitations would be added to those of nuclear radiation from fallout (especially in the case of ecosystems dominated by the relatively sensitive conifers), of smoke and smog, and so forth. Such drastic perturbations among the primary producers of the world's ecosystems (including newlyaltered relationships of competitive advantage) would in turn exert a substantial impact throughout the world on the wildlife depending upon them. Some of the animal life might also be injured directly by the enhanced UV-B radiation. This seems clear because in most instances the newly-created damaging levels would not be detected by the animals, and this would therefore preclude evasive action. Thus, for example, unavoidable damage to the cornea of the eye would reduce the efficiency of hawks, eagles, and much other wildlife, in their hunting or foraging abilities' (Westing, 1982).

It should also be noted that, in the early years following a major nuclear exchange, agro-ecosystems would be severely disrupted on a global basis by enhanced UV-B radiation (Nier et al., 1975; Kruger \& Setlow, 1982), which "damage would compound the problems resulting from radioactive contamination (to which crops, for example, are generally more sensitive than their weedy competitors and their fungal and insect pests), the smoke-and-smog pall (which would reduce productivity both directly and perhaps via adverse climatic changes), and the paucity of farmworkers, implements, fuel, fertilizers, and pesticides...' (Westing, 1982).

Although biotic recovery from nuclear devastation 'could be expected to follow more or less the normal patterns of ecological succession for the region in question - that is, to run its course over a period of decades or even centuries... this is not entirely the case [as] vegetational recovery would be hindered to the extent that seed sources would no longer be available in [the] region [while] another serious concern would be the question of ecosystem stability [and] biotic interactions, that form the very basis of an ecosystem'. The early stages of succession would be prolonged and their biomass lowered inasmuch as trees are in general more radiosensitive than shrubs, high shrubs more than low shrubs, woody plants more than herbaceous plants, and angiosperms more than mosses and lichens. A reduced biomass would result in reduced ecosystem productivityreduced, for example, by as much as $80 \%$ in a change from forest to grassland', and sometimes even more as a result of accelerated erosion. Thus although ecological succession would proceed, it would be far slower and less predictable than would normally be the case for any particular region (Westing, 1981).

In the manner of terrestrial ecosystems, oceanic and other aquatic ones would be substantially disrupted following a large-scale nuclear exchange (Tukey \& Peters, 1979; Calkins \& Thordardottir, 1980; Kruger \& Setlow, 1982). Thus marine phytoplanktonic organisms mainly inhabit the photic zone close to the surface, and their death would remove the basis of the food-chain and place in jeopardy the fish-stocks which depend on it. As it is to be expected that the UV-B radiation effect of ozone 
depletion would be more or less global, repopulation by fishes would seem 'unlikely to be rapid enough to save a major fraction of the many plankton-dependent species [and so] restoration of fish-stocks throughout the world (both commercial and otherwise) might thus in turn take 'many years to occur' (Westing, 1982).

\section{SOME ADDITIONAL THOUGHTS}

One of the many dangers to the stability of The Biosphere after any major nuclear conflict could lie in genetic consequences leading to the emergence e.g. of a lethal virus which might cause a pandemic in a weakened world (M.A. Farid, voce) or attack human brain-cells and preclude counter-measures by that unique species; another could stem from the fact that many insects tend to be more resistant to enhanced gamma radiation and UV-B radiation than the birds and other natural predators which feed on them - which could result in a world 'overrun by insects'. On the other hand there is hope that governmental leaders of major powers are now too well aware of the consequences of nuclear war to start it but what of the others, and of terrorists, bandits, lunatics, human or computer errors, and sheer accidents?

While it is necessary to emphasize that our above outlines and indications of potential environmental consequence of nuclear warfare are based on extrapolations from often very limited data, they probably underestimate ill-effects and hence err on the side of optimism. Yet the diverse impacts discussed separately, and doubtless such others as extensive disruption of communications and of supply-bases, would of course occur or commence simultaneously and, by reinforcing one another, almost certainly have far greater effects than if they had occurred separately. Such synergism is almost impossible to predict, at least quantitatively in a changed and weakened world; but if total nuclear war were ever to occur, we could visualize the impact on The Biosphere as being drastic enough to lead quite possibly to the ultimate extinction of the human species. And although it is scarcely conceivable that all life could be extinguished, especially in view of the lowly forms that are now known to extend to the very bowels of the Earth, it is quite conceivable that such forms might be alone in surviving.

\section{CONCLUSION}

There is nothing to do about nuclear war except avoid it (which means also avoiding accidental or other nuclear flare-up), and that will require destroying all current capability of waging such war and henceforth monitoring the world against any manufacture of nuclear weapons. It additionally demands a close world-wide monitoring of the civilian nuclear-power industry in order to detect and forestall possible clandestine production of weapons-grade plutonium and thence the manufacturing of nuclear weapons - including any by non-nuclearweapons-possessing states and sub-national groups (Lovins, 1980; Holdren, 1983). These avoidances are everybody's imperatives, and the more the masses of humanity are enlightened and insist on them, the sooner and more effectively will politicians prevail on governments to conform to them and save Man and Nature from the threat of annihilation.

\section{ACKNOWLEDGEMENTS}

For helpful comments on earlier drafts of this paper we are extremely grateful to Drs Frank Barnaby, Robert Goodland, Arthur Purcell, Ivan Polunin, Thomas F. Malone, Gilbert F. White, and F. Kenneth Hare.

\section{SUMMARY}

The world is threatened as never before by an insane buildup of nuclear weapons some five hundred times as strong in their explosive capacity as the latest estimate of all the chemical explosives that have ever been used throughout history. Leaders in major countries probably know the awful consequences of a nuclear war too well to start one, but the world has still to reckon with possible acts of aggression by other nations or flaring-up through technological failure, mechanical or other accident, malfunctioning or faulty feeding of computers, misinformation, neglect of machines or of constructional faults, terrorist or lunatic action, organized banditry, or the outcome of mere 'acts of God'!

The effects of nuclear war or major flare-up on the environment may be gauged from many test explosions and the two 1945 'experiments' as utterly devastating, involving fantastic blast-energy, heat-energy, radiationenergy, and various synergistic possibilities which may be expected to be far worse collectively than the total of individual ones. Particularly telling figures involving humans are that the present build-up of power of the $c a$ 50,000 nuclear warheads in existence approximates the equivalent of 3 tonnes of TNT per caput of the current world population, and that this buildup is equivalent to more than a million Hiroshima bombs.

The environmental effects of use of even a small proportion of this arsenal would include huge-scale injections of dust particles and water droplets into the stratosphere such as could have long-term outcomes in changing our climate, the addition to the troposphere of large quantities of smoke and smog to the extent of debilitating agriculture for one or more years, and the introduction of large amounts of oxides of nitrogen into the stratospheric ozone shield which, through depletion of the ozone, could permit damaging ultraviolet radiation to reach the Earth's surface on a world-wide scale. These and other indirect effects could prove highly disruptive to ecosystems both natural and man-maintained, and whether terrestrial or aquatic-even as the direct effects of nuclear warfare could kill hundreds of millions of humans outright, and huge numbers practically throughout the world more slowly and painfully through radioactive fallout.

The conclusion is inescapable that there is nothing to do about nuclear war except avoid it by destroying all current capability of waging such war and henceforth monitoring the world against any manufacture of nuclear weapons. 


\section{REFERENCES}

ANon. (1982). Declaration on prevention of nuclear war. Environmental Conservation, 9(4), pp. 339-43.

Barnaby, F. (1982). The effects of a global nuclear war: The arsenals. Ambio, 11(2-3), pp. 76-83, illustr.

BARNABY, W. (Ed.) (1982). War and Environment. Environmental Advisory Council, Ministry of Agriculture, Stockholm, Sweden: 154 pp., illustr.

Calkins, J. \& Thordardottir, T. (1980). Ecological significance of solar UV radiation on aquatic organisms. Nature (London), 283, pp. 563-6.

Crutzen, P. J. \& BiRks, J.W. (1982). Atmosphere after a total war: Twilight at noon. Ambio, 11(2-3), pp. 114-25, illustr.

Glasstone, S. (1964). Effects of Nuclear Weapons (Revised edn). United States Atomic Energy Commission, Washington, DC, USA: 730 pp., illustr.

HiatT, H.H. (1981). Foreseeable medical consequences of the use of nuclear weapons. Environmental Conservation, 8(4), pp. 263-7.

HOLDREN, J.P. (1983). Nuclear power and nuclear weapons: The connection is dangerous. Bulletin of the Atomic Scientists, 39(1), pp. 40-5, plus 39(3), p. 64

ICSU (1982). Appeal of the Executive Board of ICSU to the 2nd Special Disarmament Session of the UN General Assembly, 1982. Environmental Conservation, 9(4), p. 339.

Kruger, C. H., jr \& Setlow, R. B. (1982). Causes and Effects of Stratospheric Ozone Reduction: An Update. National Academy Press, Washington, DC, USA: xi +339 pp.

Lovins, A.B. (1980). Nuclear weapons and power-reactor plutonium. Nature (London), 283, pp. 817-23.

Nier, A.O.C. [and 7 others] (1975). Long-term Worldwide Effects of Multiple Nuclear-weapons Detonations. National
Academy of Sciences, Washington, DC, USA: xi + $339 \mathrm{pp}$.

Polunin, N. (1981). Comment: 'Plus ça change...' Environmental Conservation, 8(4), 257-8, 2 figs.

SIPRI (1982). World Armaments and Disarmament: SIPRI Yearbook 1982. Stockholm International Peace Research Institute, Bergshamra, S-171 73 Solna, Sweden, and Taylor \& Francis Ltd, London, England, UK: xii + 517 pp., illustr.

Thunborg, A.l. \& 111 others] (1981). Comprehensive Study on Nuclear Weapons. (Disarmament Study Series No. 1.) United Nations Centre for Disarmament, New York, NY, USA: vii $+172 \mathrm{pp}$

TOLBA, M.K. (1982). The Imperative of Disarmament. Environmental Conservation, 9(4), pp. 272-4.

Tukey, J.W. \& Peters, M.S. (1979). Protection Against Depletion of Stratospheric Ozone by Chlorofluorocarbons. National Academy of Sciences, Washington, DC, USA: xviii $+392 \mathrm{pp}$.

Westing, A.H. (1977). Weapons of Mass Destruction and the Environment. Taylor \& Francis, London, England, UK: xi $+95 \mathrm{pp}$.

Westing, A.H. (1980). Warfare in a Fragile World: Military

- Impact on the Human Environment. Taylor \& Francis, London, England, UK: xiv + 299 pp.

Westing, A.H. (1981). Environmental impact of nuclear warfare. Environmental Conservation, 8(4), pp. 269-73.

Westing, A.H. (1982). Guest editorial: Environmental consequences of nuclear warfare. Environmental Conservation, 9(4), pp. 269-72.

Westing, A.H., Paine, C. \& Adams, R. (1982). The race against the arms race. Environmental Conservation, $\mathbf{9}(4)$, pp. $351-2$. 